\title{
Universidade da Terceira Idade: análise de um programa pioneiro
}

\author{
Ivan Eduardo de Abreu Arruda*
}

\section{Resumo}

Neste trabalho propõe-se estudar o caso do programa brasileiro pioneiro de Universidade da Terceira Idade, organizado pela Pontifícia Universidade Católica de Campinas, por meio de uma perspectiva metodológica qualitativa. A intenção é, por meio de uma viagem histórica ao longo dos dezoito anos de atividade e fazendo uso de bibliografias, documentos e entrevistas com pessoas envolvidas, analisar os diversos aspectos que serviram como base para a construção contínua do programa, como caracterização, objetivos, currículos, infraestrutura, docentes e discentes. Considera-se que a manutenção de valores tem sido um ponto significativo na qualidade do programa, incluindo socialmente, elevando a autoestima, melhorando a qualidade de vida de seus participantes e possibilitando o fortalecimento da identidade das pessoas na terceira idade.

Palavras-chave: Programa. Idoso. Qualidade de vida. Educação.

\section{Introdução}

A opção por pesquisar a Universidade da Terceira Idade da PUC-Campinas não surgiu meramente ao acaso, foi reflexo da experiência adquirida ao longo dos últimos seis anos. Nesse período tive a oportunidade de implantar um projeto de Faculdade da Terceira Idade no interior do estado de São Paulo, bem como produzir alguns artigos científicos apresentados em congressos, tanto de âmbito nacional quanto internacional. Minhas experiências profissionais e acadêmicas com Universidades da Terceira Idade foram contributivas para me aproximar do objeto e da obtenção de produtos possivelmente marcados pela qualidade teórico-metodológica que determina o rigor científico em pesquisa. Investigar contextos envolvendo pessoas e suas relações exige alto grau de envolvimento com o problema estudado e

* Graduado em Educação Física pela Escola Superior de Educação Física de Jundiaí. Especialista em Administração Esportiva pela Universidade Federal do Paraná e em Gestão Educacional pelo Centro Universitário Monte Serrat. Mestre em Educação pela Pontifícia Universidade Católica de Campinas. Professor do curso de Educação Física da Faculdade de Pindamonhangaba. Membro do grupo de Pesquisa Qualidade de Ensino. Endereço para correspondência: Rodovia Presidente Dutra, km 99, Caixa-postal: 1041, CEP: 12422-970, Pindamonhangaba - SP. E-mail: profivanarruda@hotmail.com.

$\hookrightarrow$ Recebido em junho de 2009 - Avaliado em março de 2010.

$\hookrightarrow$ doi:10.5335/rbceh.2010.009 
de comprometimento com a fidelização, a validade e a aplicação dos resultados encontrados.

Apesar de este trabalho se inserir num quadro de dúvida, principalmente em relação às possibilidades de generalização, trata-se de um caso pioneiro e exemplar que merece ser conhecido e estudado. Assim, a problematização voltou-se à percepção dos valores e dos aspectos incutidos na perspectiva da Universidade da Terceira Idade enquanto referência nacional de trabalho educacional com idosos. No estudo utilizaram-se análise documental e entrevistas semiestruturadas com professores, alunos e coordenação do programa. Esta pesquisa teve consentimento do Comitê de Ética e Pesquisa da PUC-Campinas, sob o protocolo 830/07, de 28 de novembro de 2007. Os documentos analisados foram: o projeto pedagógico do programa, publicações relativas à organização da Universidade da Terceira Idade da PUC-Campinas, materiais usados para divulgação e também algumas autoavaliações respondidas pelos alunos das turmas de 1990 e 1999. Na entrevista semiestruturada, dez pessoas responderam aos questionamentos: seis alunos, três professores e uma representante da coordenação da Universidade da Terceira Idade.

Aos alunos coube responder ao seguinte roteiro: Como soube do programa? Ao longo desses anos, houve uma disciplina, uma palestra, ou também um professor que a marcou de alguma forma? Considera adequada a infraestrutura que a PUC oferece para este programa, os acessos, as salas de aula?
Os professores estão preparados para lidar com a terceira idade? Como analisa a presença feminina entre os alunos do programa? O que diria a uma pessoa disposta a iniciar um programa como esse? Como a família a vê participando da Unati? Que sugestões poderiam fazer pensando na qualidade do programa? $\mathrm{O}$ que pensa sobre o preço das mensalidades do programa?

Os professores foram submetidos a outro roteiro: Qual sua experiência profissional com a terceira idade antes de lecionar no programa? O que te motivou a trabalhar no programa? Considera adequados a infraestrutura e os recursos materiais e didáticos para ministrar as aulas no programa? Os objetivos da sua disciplina foram alcançados? Acredita que sua disciplina possa ter mudado algo na vida dos alunos? Considerando 0 aluno da terceira idade, houve necessidade de adaptações na didática? De que tipo? Houve crescimento profissional ao participar do programa? Que sugestões poderia fazer pensando na qualidade do programa?

Para a coordenação do programa foi utilizado o seguinte roteiro: como se encontra o curso? Como se deu a idéia e o início do programa? Sobre as nomenclaturas: a universidade é da terceira idade, é para a terceira idade, ou é aberta à terceira idade? E quem é a terceira idade? Tanto os objetivos quanto a estrutura curricular sofreram mudanças ao longo desses dezoito anos? Como se dá a relação entre alunos de classe econômica e grau de instrução diferenciados? As promulgações da lei 9.394, de 1996 (Diretrizes e Bases da 
Educação Nacional), e da lei 10.741, de 2003 (Estatuto do Idoso) interferiram no andamento do programa? Há relação entre os cursos da PUC-Campinas, graduação e pós-graduação, e a Universidade da Terceira Idade? Como a PUC-Campinas apoia administrativamente o programa? Considera adequados a infraestrutura e os recursos materiais e didáticos utilizados no programa? Considera importante que a coordenação do programa esteja presente em sala de aula? O que falta para se ter o "Programa dos Sonhos"? O que espera do futuro das Universidades da Terceira Idade brasileiras? Como observa a ação do Ministério da Educação nessa questão?

Este trabalho foi construído buscando-se compreender a caracterização da Universidade da Terceira Idade da PUC-Campinas, bem como seu objetivo, currículo, infraestrutura, seus professores e seus alunos na perspectiva da inclusão social, da qualidade de vida e da autoestima.

\section{Caracterização}

Os dados coletados evidenciam que a Universidade da Terceira Idade surgiram como um curso de extensão universitária, por meio de uma ação coletiva entre representantes e professores da PUC-Campinas, baseado em uma pesquisa que mostrava a situação social do idoso campineiro na época. Os programas de Universidade da Terceira Idade tiveram uma ascensão rápida no país, o que denotou uma demanda reprimida dos idosos, pois bastou se criar uma proposta coesa e objetiva dentro de uma instituição universitária para que esse público endossasse a nova ideia, fato que se evidenciou também no caso estudado. O projeto pedagógico inicial considera a Universidade da Terceira Idade uma atividade acadêmica e sociopolítica voltada a um público específico da população local e regional, no caso, as pessoas de meia-idade e da terceira idade. (MARTINS DE SÁ, 1991).

No transcorrer da pesquisa, observando a fala de alguns sujeitos, bem como alguns documentos, pôde-se perceber que a Universidade da Terceira Idade da PUC-Campinas era denominada ora como curso de extensão, ora como projeto e ora como programa. Essa constatação me fez indagar: Qual, afinal, a caracterização da Universidade da Terceira Idade: curso, projeto ou programa? Por curso de extensão entende-se a unidade integral de ensino-aprendizagem que tem por finalidade proporcionar a aquisição de conhecimentos exigidos no domínio de um assunto, constituído pela articulação de conteúdos na aplicação de metodologias, técnicas de ensino e avaliação de resultados. (BELLINASO, 2005).

A coordenação da Universidade da Terceira Idade, bem como seu projeto pedagógico, trata esta atividade como sendo um curso de extensão universitária e atualização cultural. Caracteriza-se como curso também pelo fato de estar, inicialmente, vinculado à Faculdade de Serviço Social, sendo uma possibilidade extensionista. Atualmente, não responde mais à Faculdade de Serviço Social e, sim, ao Núcleo de Pesquisa e Extensão do Centro de Ciências Sociais 
Aplicadas, o que reforça a ideia de curso de extensão.

Pensando na caracterização da Universidade da Terceira Idade como projeto e na duração do programa em um ano e meio, Marino (2003) destaca que projetos são atividades ofertadas por um determinado período. Cohen e Franco (2003) também debatem essa questão afirmando que projetos são empreendimentos planejados caracterizados pelo conjunto de atividades relacionadas entre si e coordenadas para atingir objetivos específicos, respeitando orçamento e período de tempo. A estrutura curricular da Universidade da Terceira Idade, dividida cronologicamente em três semestres, indica que se trata de um projeto organizado e com finalidades bem claras e prazos de integralização dos conteúdos preestabelecidos. Já os programas, de acordo com Cohen e Franco (2003), são conjuntos de projetos que buscam os mesmos objetivos. Para Marino (2003) programas são atividades oferecidas continuadamente.

Osório (2005), em seu trabalho sobre os programas socioeducativos com idosos na Espanha, explica que os programas não são atividades ocasionais, bem como também não são projetos circunstanciais; todavia, são projetos que permanecem no tempo de forma estável. Na perspectiva educacional, o autor prossegue enfatizando que os programas são caracterizados por uma denominação e um marco institucional consolidado e socialmente reconhecido.

Ao observarmos a possibilidade de permanência e de sequência que a Universidade da Terceira Idade possibilita aos seus alunos, visto que há idosos matriculados desde 1990, compreendemos que essa longevidade alcançada pelo projeto pode levar à compreensão de que se trata de um programa. Um aluno presente no curso há dezoito anos e que ali permanece, provavelmente, vivenciou desafios, obteve superações e alcançou objetivos distintos, superando o escopo de um projeto, pois de outra forma seria difícil pensar em sua permanência por tanto tempo, repetindo as mesmas atividades.

Essa suposta renovação de objetivos soma-se à afirmação de Osório ao concluir e caracterizar a Universidade da Terceira Idade como programa, pois os projetos têm vida mais curta e os cursos de extensão não poderiam ter tal renovação e continuar sendo o mesmo curso. $\mathrm{O}$ aluno não se matricula para participar de um curso ou de um projeto com a informação que a duração será de dezoito anos, pois não é esta a proposta, mas a prática o faz adquirir tais características para alguns de seus alunos. Para boa parte, no entanto, constitui espaço de criação de vínculos duradouros.

"Nós até temos uma turminha da primeira turma que todo ano a gente se reúne no fim do ano. E a gente faz uma reuniãozinha na casa de alguma pessoa, em uma casa maior, e faz um almoço [...] A gente organiza as lembrancinhas para dar para todos e a gente passa uma tarde muito gostosa, com todo mundo alegre, todo mundo contando como passou o ano. A gente ainda continua com essa amizade, desde 1990. Alguns já se foram, infelizmente, mas a gente continua aquele grupo unido, é muito bom.” (Aluna A)

$\mathrm{O}$ fato de se caracterizar como projeto, curso ou programa não desvincula a Universidade da Terceira Idade, pio- 
neira no ramo, de seu pertencimento às ações de extensão da instituição. Disso se pode depreender que a própria instituição de ensino superior reconheceu a importância da questão muito antes das congêneres e concebeu um programa que explicita características de sua natureza comunitária. Pioneirismo, valores históricos, ser maior que projeto pela longevidade, extrapolar um simples curso de extensão, não ter objetivos que se resumem à certificação, função social de inclusão, de melhoria da qualidade de vida e trabalho com autoestima fazem a Universidade da Terceira Idade adquirir dimensões muito peculiares. Em síntese, e buscando expressar reconhecimento dessa natureza, chamarei de "programa", mesmo compreendendo as dificuldades para uma caracterização exata.

\section{Objetivos}

O programa foi construído segundo pressupostos relativos a universidade, questões sociais à terceira idade e políticas sociais à terceira idade. (MARTINS DE SÁ, 1998). Os pressupostos relativos à universidade consideram que é de responsabilidade da instituição de ensino superior a crítica teórica rigorosa sobre as questões sociais; a universidade constitui-se num espaço privilegiado ao intercâmbio, à complementação, à influência e à modificação entre a instituição e os órgãos da sociedade política, a sociedade civil e os movimentos populares.

Quanto aos pressupostos referentes às questões sociais à terceira idade, indicam que essas questões se inserem na totalidade histórico-social, expressando suas contradições e determinações; o progressivo distanciamento das necessidades do idoso em relação às políticas sociais; a situação do idoso na realidade do país. Em relação aos pressupostos referentes às políticas sociais à terceira idade, apontam que essas políticas privilegiam a constituição da cidadania; as mudanças qualitativas nas políticas sociais dependem de propostas hegemônicas resultantes de relações recíprocas entre organizações sociais, acadêmicas e científicas, e organizações populares.

Tais pressupostos formaram o contexto definidor dos objetivos iniciais do programa que se tornou referência de discussão para as Políticas de Atenção ao Idoso, delineadas na década de 1990 e início do decênio de 2000. Os objetivos do programa a partir de então foram promover a educação permanente e estimular a inserção social dos idosos. Para tal utilizou-se um trabalho interdisciplinar voltado à comunidade. $\mathrm{O}$ depoimento da coordenação do programa apresentado a seguir é elucidativo desse processo:

"A Universidade da Terceira Idade ajudou a impulsionar, antes do Estatuto, a lei 8.842 que propõe a Política Nacional do Idoso. Verifica-se nessa Lei o item referente às universidades da terceira idade. Isso foi uma contribuição muito grande deste curso. Nós participamos ativamente das discussões [...] O Estatuto do Idoso retoma, fala novamente em Universidade da Terceira Idade como direito, então você vê que foi uma conquista dos próprios idosos. A contribuição foi daqui para lá e não a interferência de lá para cá. Agora, em termos da LDB [...] ela é muito clara privilegiando aí a extensão, acho que também é uma contribuição no outro sentido, a PUC tem dado uma contribuição muito rica, muito grande, em termos de extensão universitária e a Universidade da Terceira Idade está nesse pacote." (Coordenação) 
As afirmações da coordenação sobre Política Nacional do Idoso, Estatuto do Idoso e LDB em relação com os pressupostos apresentados anteriormente parecem indicar que se buscou cumprir os objetivos iniciais do programa nos dezoito anos de sua existência. Essa longevidade também pode indicar que os objetivos da Universidade da Terceira Idade para com seus alunos e a comunidade têm sido atingidos mesmo que em parte.

\section{Currículo}

Martins de Sá (1998) explica que no programa se oferece um currículo organizado em três níveis semestrais subseqüentes, considerando o idoso como um ser pluridimensional e unitário; a possibilidade de se aprender a unidade ou a totalidade na dialética entre as partes e o todo; a compreensão da natureza interdisciplinar inerente à gerontologia; a oportunidade de articular conteúdos, técnicas e instrumentos e a ocupação do espaço universitário. O primeiro nível aborda a atualização cultural, a integração, a identidade pessoal, a sensibilização e a proposta para um novo projeto de vida. O segundo nível responsabiliza-se pelo aprofundamento e pela preparação para formar círculos de estudos e possíveis monitores. O terceiro e último nível foca as relações entre gerações.

Todos os níveis do curso são rodeados por módulos didáticos interdisciplinares, estruturados sobre a base de várias disciplinas científicas, não havendo hierarquia entre eles. São eles: aspectos biológicos do envelhecimento; aspectos psicossociais da terceira idade; o idoso e a sua situação socioeconômica e legal; a cultura na terceira idade; educação física, recreação e lazer na terceira idade; a organização político-social na terceira idade; vivência na terceira idade e estágios supervisionados. O módulo que trata dos aspectos biológicos do envelhecimento procura explicar o processo básico do envelhecimento em suas características fisiológicas, genéticas e imunológicas e em nível celular, abrangendo também a saúde e a sexualidade na terceira idade, a compreensão do corpo e do tempo e as políticas sociais no campo da saúde.

O módulo dos aspectos psicossociais da terceira idade destina-se às questões de personalidade, comportamento, atitudes e aptidões, alterações sensoriais e perceptivas, angústia, ansiedade, estresse, relações humanas, comunicação e psicopatologia. O módulo do idoso e a sua situação socioeconômica e legal visa situar o idoso em seu contexto por meio de temáticas relacionadas à demografia e à economia, explicitando a legislação voltada à velhice e as políticas sociais contemporâneas.

A cultura na terceira idade é um módulo que estuda a cultura e a evolução humana, jornalismo, artes, música, teatro, dança, folclore, tradições, filmes, turismo, ecologia, informática e engenharia. Já o módulo sobre educação física, recreação e lazer na terceira idade refere-se a um conjunto de conhecimentos destinados à manutenção da saúde e da forma física na terceira idade, bem como busca-se orientar a ocupação do tempo livre por meio da manifestação lúdica. O módulo da organização político- 
social na terceira idade possibilita a elevação do grau de consciência crítica e de mobilização, participação e organização social do idoso enquanto cidadão. $\mathrm{O}$ módulo referente à vivência na terceira idade contribui na análise de experiências cotidianas do idoso, enfocando as vidas familiar, política, moral, cívica, artística, científica, cultural, ocupacional e religiosa.

Para terminar, o módulo dos estágios supervisionados preocupa-se com a orientação de atividades práticas de qualquer natureza, realizadas pelo aluno na própria PUC-Campinas, nos projetos comunitários, nas organizações populares e em outras instituições. É importante frisar que essa estrutura modular não vigorou durante todos esses anos. Dias (2000) constatou em sua pesquisa que no final da década de 1990, influenciado pela relação receita/ despesa, o programa substituiu as aulas formais por frequentes palestras, o que, segundo a autora, desmotivou os alunos, refletindo, assim, em parcial abandono e mostrando a necessidade dos alunos de criar vínculo com o profissional que ali estava para ministrar seu conteúdo.

Entendo que as palestras perdem a essência da organização de uma aula, distanciando o idoso da proposta e prejudicando, inclusive, a construção das atividades em grupo. Além desses oito módulos que contemplam os três níveis semestrais do programa aplicados entre segundas e quartas-feiras, há também na organização curricular, nas terças, quintas e sextas-feiras, as atividades optativas, que compreendem as oficinas, as atividades culturais, sociorrecreativas e religiosas e os cursos de aprofundamento permanente, quando se reúnem alunos de diferentes cursos, períodos e turmas. As oficinas ofertadas atualmente são informática, internet, português, inglês, espanhol, coral, dança, oficina do corpo, postura e beleza, relações interpessoais, jogos recreativos, contadores de história, oficina instrumental, entre outras sugeridas no transcorrer do programa.

A coordenação reforça que o projeto pedagógico e a organização curricular flexível são aspectos importantes do programa, havendo um processo avaliativo e participativo dos alunos, que vai apontando as possíveis mudanças ou interferências para atender aos interesses dos alunos, sem perder de vista o eixo comum. O projeto pedagógico vem sendo aprimorado, porém procura-se manter a mesma proposta. A meu ver, o projeto pedagógico é o mesmo desde o início; o que difere são os próprios apontamentos dos alunos em termos de assuntos a serem trabalhados, bem como as orientações ao corpo docente em ministrar aulas com inovação e ineditismo, adjetivos que resultam na motivação à permanência $\mathrm{e}$ assiduidade no programa.

Os alunos são considerados por seus professores como sujeitos de conhecimento, seres capazes de aprender e como pessoas que merecem respeito e consideração, como fica evidenciado no trecho a seguir, onde o docente se coloca claramente numa postura freireana (FREIRE, 1996) de estabelecimento de diálogo com os alunos e com o conhecimento: 
Quando o educador toma a palavra na sala de aula, ele o faz em relação com os alunos. Parte da situação dos alunos, de suas vidas, de seus interesses, especialmente dos temas que os envolvem e que os problematizam. $\mathrm{O}$ diálogo, o respeito, a história de vida expressam a riqueza do conteúdo que vai sendo trabalhado, refletido, criando uma relação de intencionalidade professor-aluno. É nesta relação que se fundamenta o sentido dos alunos estarem ali, discutindo a sua prática existencial. (Docente A).

A organização curricular busca construir módulos com base nas necessidades e interesses dos idosos indicados em avaliação do programa. Os temas indicados em uma dessas avaliações são apresentados a seguir, a fim de se buscar identificar as relações desses com os objetivos expressos para os módulos. Nessas avaliações os alunos optam por cinco dos diversos núcleos temáticos ofertados. Para alunos do primeiro nível há as opções o processo biológico do envelhecimento; aspectos médico-sociais na terceira idade; odontologia na terceira idade; nutrição na terceira idade; aspectos psicológicos da terceira idade; 0 idoso na realidade brasileira; literatura e terceira idade; turismo e terceira idade; música; criatividade na terceira idade; informática; trabalho e ocupações na terceira idade; autoconhecimento; conhecimento do outro; a relação idoso-família; o idoso e seu relacionamento social; as leis de proteção à terceira idade; aposentadoria; educação continuada; memória histórica; as limitações, o potencial e as possibilidades da pessoa idosa; a organização social e política na terceira idade e voluntariado na terceira idade.
Para os alunos do segundo e terceiro níveis encontram-se algumas alterações de opções: o processo biológico do envelhecimento; aspectos médicosociais na terceira idade; odontologia na terceira idade; nutrição na terceira idade; primeiros socorros; fisioterapia; aspectos psicológicos da terceira idade; dinâmica de grupo; o idoso na realidade brasileira; educação continuada ou educação permanente; literatura e terceira idade; letras: português, inglês, espanhol, francês; turismo e terceira idade; música; criatividade na terceira idade; informática; ecologia; filosofia; história geral; sociologia; trabalho e ocupações na terceira idade e geografia.

Nas respostas dadas pelos alunos das turmas de 1990 e 1999, que fazem parte dos sujeitos desta pesquisa, constatei que o primeiro item - "aspectos biológicos do envelhecimento" - de todos os níveis acima é o núcleo temático mais citado, o que mostra a preocupação dos idosos com as naturais mudanças fisiológicas e seus possíveis impactos na vida pessoal, familiar e social.

Para finalizar a questão curricular, entendo ser necessário também repensar algumas práticas dentro do programa, principalmente a educação física. Apesar de o programa, sutilmente, contemplar a educação física, a recreação e o lazer como conteúdo modular, fica nítida nas autoavaliações e nas falas de alguns alunos entrevistados a necessidade de se explorar melhor a temática educação física. Os alunos mostram extrema preocupação com aspectos biológicos do envelhecimento, o que reforça ainda mais a necessidade de o programa buscar maior proximidade com a educação física. 
A recreação e a dança vivenciadas no programa têm, naturalmente, seus valores lúdicos, culturais e físicos, porém a educação física, com sua riqueza de possibilidades, me faz acreditar que os alunos do programa, dentro do limite físico individual, possam experimentar outras vivências.

\section{Infraestrutura}

No começo, as atividades da Universidade da Terceira Idade eram desenvolvidas no Instituto de Letras da PUCCampinas, em virtude da facilitação da acessibilidade do idoso pelo fato do prédio contar com elevador. Entretanto, o sucesso do programa fez as turmas se multiplicarem, com o que o espaço tornou-se insuficiente. Assim, houve a necessidade de mudança para o prédio central da instituição, local que recebe a terceira idade até hoje. (DIAS, 2000). Em uma ocasião, o programa chegou a ser oferecido em outro campus da instituição, distante do centro da cidade, fato que culminou com uma baixa procura, $o$ que o fez retornar ao campus central. "O que eu mais gosto aqui é o acesso aqui no centro da cidade. É ótimo." (Aluna D)

Coordenação, docentes e alunos acreditam que o curso tende a progredir com sua sede continuando na região central da cidade. Experiências realizadas no Campus I foram extremamente negativas, pois a questão da locomoção é fator determinante no sucesso do curso. É importante reforçar que essa é uma característica desse programa. Tive uma experiência também no interior de São Paulo, onde a Faculdade da Terceira
Idade localizava-se em bairro afastado, o que, contudo, não impediu o acesso e o sucesso das atividades.

Entendo que, pelo fato de o programa ter iniciado e permanecido na região central por muitos anos, qualquer mudança nesse sentido levaria a um desconforto por parte dos alunos. Sobre a estrutura, detectei que a Universidade da Terceira Idade dispõe de prédio com amplo pátio, copiadora, aconchegante auditório, higienizados sanitários adaptados às possíveis limitações físicas dos idosos, agência bancária, além de salas de aula espaçosas. Os recursos didáticos da graduação encontram-se também à disposição da Universidade da Terceira Idade.

"Dentro das possibilidades da própria Universidade acredito que o programa recebe o apoio necessário para o seu desenvolvimento. Acredito que são oferecidas ao programa as mesmas condições que tem os outros cursos da PUC.” (Docente A)

Os alunos e o corpo docente indicam satisfação não só com a localização central, mas também com a estrutura: "As salas agora estão boas, todas modernas, ventilador e tudo". (Aluna A). Como itens cabíveis à mudança classifico as escadarias de acesso ao auditório e a outros espaços da instituição e a estreita e pequena sala de recepção, cujas funções são executadas por uma secretaria.

“Têm alunos que não querem subir escada, têm outros que não ligam”. (Aluna B)

"Eu não me importo com as escadas, subo bem, mas têm alguns alunos que reclamam [...]. Lembro de um momento que as aulas foram lá embaixo por causa de uma aluna cadeirante". (Aluna C) 
É importante frisar que, quando me refiro à mudança, não significa necessariamente uma interferência de ordem estrutural. Fica evidente que para os alunos o acesso à Universidade da Terceira Idade na região central de Campinas é visto positivamente. Muitos deles residem próximo, há meio de transporte público, além da facilidade para alguém da família levar e/ou buscar.

\section{Docentes}

Uma pesquisa do Programa de Mestrado em Educação da PUC-Campinas realizada em 2003 constatou o perfil dos professores atuantes na Universidade da Terceira Idade. Os dados mostraram no corpo docente a presença marcante de mulheres entre cinquenta e setenta anos, muitas delas com formação acadêmica em serviço social e com treze anos ou mais atuando no programa. A maioria dos professores vê os alunos como motivados, envolvidos e questionadores. Para o corpo docente, o ato de lecionar para esse público significa um importante momento de troca de experiências. (OLIVEIRA, 2004).

A Universidade da Terceira Idade da PUC-Campinas conta com quase cem professores e coordenadores de diversas áreas do conhecimento. No biênio 20042005 houve a participação de noventa professores, que ministraram, aproximadamente, 585 horas-aula. (MARTINS DE SÁ, 2005).

No programa há docentes internos e externos à PUC-Campinas. O perfil aguardado desse professor é que ele tenha interesse e sensibilidade natural para lidar com alunos da terceira idade, bem como conheça aspectos básicos da gerontologia e do envelhecimento. (MARTINS DE SÁ, 1991). Esse perfil esperado se torna utópico a partir do momento em que observo nas entrevistas com os professores que nenhum possuía experiências anteriores com esse público, sequer formação específica. Entretanto, cabe ressaltar que a qualidade dos professores de se adaptarem a novos cenários pedagógicos conduz a que esse agravante não se torne motivo de depreciação do programa, mesmo porque muitos desses, pelo fato de lecionarem por vários anos no programa, construíram suas experiências profissionais com a terceira idade na convivência com os próprios alunos.

No corpo docente, os alunos entendem as diferenças existentes entre os professores, mas os veem de forma positiva no programa, dispostos a aprender também com o público da terceira idade. Isso se confirma pela fala dos professores ao relatarem que os testemunhos de vida dos seus alunos e as riquezas dos encontros com eles os educam de alguma forma, e também pela fala de algumas entrevistadas sobre os professores do programa: "A gente não sente a idade que tem porque os professores não discriminam." (Aluna E)

"Olha, a meu ver [...] são ótimos [...] Às vezes tem um comentário e eu falo, olha gente, para mim eu não vejo nada. Se aquela aula não é aquela coisa maravilhosa, mas a gente sempre tira alguma coisa, eu sempre tiro, então, para mim, eu não posso falar nada, são sempre ótimos, desde que começou o programa." (Aluna A)

Como sugestão oferecida pelo corpo docente do programa, acredita-se que 
a PUC-Campinas necessita explicitar, com base em sua missão e objetivo, a importância de ter em seus quadros este programa e de se comprometer ainda mais para a sua continuidade. Outra preocupação docente é que os professores do programa tenham amor àquilo que estão propondo aos idosos. Essas propostas docentesm, somadas a um excelente relacionamento com seus alunos da terceira idade, fazem do professor uma possibilidade de caminho para que o aluno se inclua socialmente, melhore sua autoestima e atinja a qualidade de vida.

\section{Alunos}

A coordenação do programa fez, recentemente, uma caracterização do alunado da Universidade da Terceira Idade. Aproximadamente 90\% dos alunos são aposentados ou vivem do rendimento do cônjuge. Foram encontrados alunos de outros municípios e a faixa etária obedece ao proposto pelo projeto pedagógico, uma vez que há pessoas matriculadas a partir de 45 anos, o que se coloca em acordo com o que estabelece a OMS para a caracterização das pessoas de meia-idade.

Nas entrevistas realizadas especificamente para este trabalho houve equilíbrio nas opiniões dos alunos quando questionados sobre as onze mensalidades de $R \$ 115,00$ da Universidade da Terceira Idade; alguns as consideram fora do orçamento, ao passo que para outros não representam problema. Não vejo como cabível reduzir o custo a zero para os alunos, mas creio ser possível repensar outras formas para se equi- librar receita/despesa do programa, por exemplo, criação de convênios com associações ou empresas voltadas à terceira idade ou financiamento de órgãos governamentais.

É prática consagrada no programa realizar anualmente autoavaliações, das quais alguns resultados foram utilizados nesta pesquisa. Na autoavaliação, composta por quinze questões, foi possível observar itens pertinentes aos alunos. A seguir, verificaremos uma dessas questões, submetida a sessenta alunos das turmas de 1990 e 1999, com a respectiva resposta encontrada. "Qual o motivo que o levou ao curso?" As duas respostas mais assinaladas por ambas as turmas foram: "atualizar conhecimentos"; e "conviver com pessoas da mesma idade". Considero que fica evidente a preocupação com a revigoração da autoestima.

Buscar novos conhecimentos e compreender o ser da mesma faixa etária torna-se atributo para que os alunos se encontrem nessa nova fase da vida. É também o que se pôde comprovar com algumas entrevistas realizadas:

"Eu fiquei viúva, estava muito triste e daí a minha filha foi na médica dela e a médica comentou da Universidade da Terceira Idade à minha filha e falou para que eu procurasse saber. Vim, estou alguns anos, muito feliz e até desfilo na oficina de moda que tem aqui." (Aluna B)

A Universidade da Terceira Idade não pode ser considerada elitista, pois mais de $50 \%$ de seus alunos se encontram na faixa econômica de um a três salários mínimos. A diferença financeira entre eles resulta também em diferença cultural e até de grau de instrução. 
Nesse sentido, o curso foi iniciado em 1990 com duas turmas divididas por escolaridade: uma turma com alunos alfabetizados e com primeiro grau completo e outra turma de alunos com segundo grau e ensino superior completo. Contudo, ao se perceber que os professores aplicavam os mesmos conteúdos às duas turmas e que a qualidade do aprendizado era semelhante, optou-se por unificar as turmas a partir do semestre seguinte da inauguração.

Caberia aqui uma longa discussão sobre elite. Entretanto, percebo que a PUC-Campinas, como instituição tradicional na cidade, carrega consigo esse estigma de elitismo. Quanto à reorganização das turmas por grau de instrução, vejo que essa modificação foi necessária, não só pelo próprio conteúdo aplicado, mas também em virtude dos objetivos do programa.

\section{Considerações finais}

$\mathrm{Na}$ Universidade da Terceira Idade da PUC-Campinas a manutenção desses valores (objetivos, currículo, localização e docentes), representados por uma natureza construída ao longo dos anos, tem sido um tópico de extrema importância para a qualidade do programa. Esses se vêm explicitados como valores na prática pela longa permanência de muitos alunos do programa no cumprimento dos objetivos, na não substituição frequente de docentes e no relacionamento professor-aluno, na não modificação do projeto pedagógico do curso, além da fixação do ambiente das aulas no mesmo local.
Tais valores resultam em fortalecimento de identidade, que ajuda os alunos noutras situações e espaços, como os de suas moradias e de suas famílias. Isso se reflete no idoso fazendo-o sentir-se um sujeito incluso socialmente, melhorando sua autoestima e possibilitando a ele uma constante manutenção da qualidade de vida.

Encerro frisando que este trabalho não representou em momento algum a verdade única e absoluta, porém esperase que possa orientar novas pesquisas em nível de graduação e pós-graduação, bem como servir como referência para discussões no programa. A Universidade da Terceira Idade da PUC-Campinas, por sua idade e pela sua qualidade e riqueza no atendimento ao idoso, conta com um imenso arquivo documental e humano, possibilitando inúmeros estudos.

University of the Third Age: analysis of a pioneer program

\section{Abstract}

This work proposes to study the case of the Brazilian pioneer of the program University of the Third Age organized by the Pontifical Catholic University of Campinas using a qualitative methodological perspective. The intention, through a historical journey over eighteen years of activity and making use of bibliographies, documents and interviews with people involved, is to examine the various aspects that served as basis for the continuous building of the program, such as characterization, objectives, curricula, infrastructure, teachers and students. It is considered that the maintenance of values has been a significant point in the quality of the program, including socially, 
raising self-esteem and improving quality of life of its participants, allowing the strengthening of the identity of persons in old age.

Key words: Program. Aged. Quality of life. Education.

\section{Referências}

BELLINASO, T. B. Uma atividade à la carte. Ensino Superior, São Paulo, a. 7, n. 84, p. $40-45$, set. 2005.

COHEN, E.; FRANCO, R. Avaliação de projetos sociais. Petrópolis: Vozes, 2003.

DIAS, M. C. O. S. Avaliação de um projeto pedagógico de uma Universidade da Terceira Idade: múltiplos olhares e vozes. 2000 . S. f. Dissertação (Mestrado em Educação) - Faculdade de Educação da Pontifícia Universidade Católica de Campinas. Pontifícia Universidade Católica de Campinas, Campinas, 2000.

FREIRE, P. Pedagogia da autonomia. Rio de Janeiro: Paz e Terra, 1996.

MARINO, E. Diretrizes para avaliação de projetos e programas de investimento social privado. 2003. 198 f. Dissertação (Mestrado em Administração) - Faculdade de Economia, Administração e Contabilidade da Universidade de São Paulo, Universidade de São Paulo, São Paulo: 2003.

MARTINS DE SÁ, J. L. A Universidade da Terceira Idade na PUCCAMP. Proposta e ação inicial. Campinas: Faculdade de Serviço Social, 1991.

- Da Universidade da Terceira Idade para a comunidade: educação popular $\mathrm{x}$ educação acadêmica. Cadernos de Serviço Social, Campinas: Núcleo de Políticas Sociais e Serviço Social, 1998.

. A Universidade da Terceira Idade gerando extensão, pesquisa e ensino. Cadernos de Extensão, Campinas: PUC-Campinas/ PROEXT, 2005.
OLIVEIRA, V. R. A construção da relação professor-aluno em uma Universidade da Terceira Idade. Campinas, 2004. S. f. Dissertação (Mestrado em Educação) - Faculdade de Educação da Pontifícia Universidade Católica de Campinas. Pontifícia Universidade Católica de Campinas, Campinas: 2004.

OSORIO, A. R. Intervención educativa con personas mayores: análisis de diversos programas en el contexto español. In: CONGRESSO IBEROAMERICANO SOBRE EXPERIÊNCIAS EDUCATIVAS UNIVERSITÁRIAS COM IDOSOS, I. 2005. Anais... Lima, Peru: Pontifícia Universidade Católica, 2005. 